steroid hormone contraception. Venous thromboembolic disease and combined oral contraceptives: results of international multicentre case control study. Lancet 1995;346:1575-82.

3 Jick H, Jick SS, Gurewich V, Myers MW, Vasilakis C. Risk of idiopathic cardiovascular death and non-fatal venous thromboembolism in women using oral contraceptives with differing progestogen components. Lancet 1995:346:1589-93.

4 Spitzer WO, Lewis MA, Heinemann LA, Thorogood M, MacRae KD. Third generation oral contraceptives and risk of venous thromboembolic disorders: an international case-control study. Transnational Research Group on Oral Contraceptives and the Health of Young Women. BMJ 1996;312:83-8.

5 Mayor S. Department of Health changes advice on third generation pills. BMJ 1999;318:1026.

6 Parkin L, Skegg DCG, Wilson M, Herbison GP, Paul C. Oral contraceptives and fatal pulmonary embolism. Lancet 2000;355:2133-4.

7 Bloemenkamp KW, Rosendaal FR, Buller HR, Helmerhost FM, Colly LP, Vandenbroucke JP. Risk of venous thrombosis with use of current low-dose oral contraceptives is not explained by diagnostic suspicion and referral bias. Arch Int Med 1999;159:65-70.

8 Mellemkjaer L, Sorenson HT, Dreyer L, Olsen J, Olsen JH. Admission for and mortality from primary venous thromboembolism in women of fertile age in Denmark, 1977-95. BMJ 1999;319:820-1.

9 Suissa S, Blais L, Spitzer WO, Cusson J, Lewis M, Heinemann L. First-time use of newer oral contraceptives and the risk of venous thromboembolism. Contraception 1998;57:61-5.
10 Lidegaard O, Edstrom B, Kreiner S. Oral contraceptives and venous thromboembolism: a case-control study. Contraception 1998;57:291-301. 11 Lewis MA, MacRae KD, Kuhl-Habichl D, Bruppacher R, Heinemann LA Spitzer WO. The differential risk of oral contraceptives: the impact of full exposure history. Hum Reprod 1999;14:1493-9.

12 Farmer RDT, Lawrenson RA, Thompson CR, Kennedy JG, Hambleton IR. Population-based study of risk of venous thromboembolism associated with various oral contraceptives. Lancet 1997;349:83-8.

13 Farmer RDT, Lawrenson RA, Todd J-C, Williams TJ, MacRae KD, Tyrer F, et al. A comparison of the risks of venous thromboembolic disease in association with different combined oral contraceptives. $\mathrm{Br}$ I Clin Pharmacol 2000;49:580-90.

14 Jick H, Jick SS, Derby LE. Validation of information recorded on the general practitioner based computerised data resource in the United Kingdom. BMJ 1991;302:766-8.

15 Lawrenson R, Todd J-C, Leydon GM, Williams TJ, Farmer RDT Validation of the diagnosis of venous thromboembolism in general practice database studies. Br J Clin Pharmacol 2000;49:591-6.

16 StataCorp. Stata statistical software release 5.0. College Station, TX: Stata Corporation, 1997.

17 Lawrenson RA, Whalley A, Simpson E, Farmer RDT. DoH seems to have underestimated incidence of venous thromboembolism in users of combined oral contraceptives. BMJ 1999;319:387.

(Accepted 12 July 2000)

\title{
Qualitative interview study of communication between parents and children about maternal breast cancer
}

\author{
Jacqueline Barnes, Leanda Kroll, Olive Burke, Joanna Lee, Alison Jones, Alan Stein
}

\begin{abstract}
Objective To examine parents' communication with their children about the diagnosis and initial treatment of breast cancer in the mother.

Design Qualitative interview study within cross sectional cohort.

Setting Two breast cancer treatment centres. Participants 32 women with stage I or stage II breast cancer with a total of 56 school aged children.

Main outcome measures Semistructured interview regarding timing and extent of communication with children about the diagnosis and initial treatment of the mother's illness, reasons for talking to children or withholding information, and help available and requested from health professionals.

Results Women were most likely to begin talking to their children after their diagnosis had been confirmed by biopsy, but a minority waited until after surgery or said nothing at all. Family discussion did not necessarily include mention of cancer. There was considerable consistency in the reasons given for either discussing or not discussing the diagnosis. The most common reason for not communicating was avoidance of children's questions and particularly those about death. While most mothers experienced helpful discussion with a doctor concerning their illness, few were offered help with talking to children; many would have liked help, particularly the opportunity for both parents to talk to a health professional with experience in understanding and talking to children.
\end{abstract}

Conclusions Parents diagnosed with cancer or other serious illnesses should be offered help to think about whether, what, and how to tell their children and about what children can understand, especially as they may well be struggling themselves to come to terms with their illness.

\section{Introduction}

In the past 10 years there has been increased acknowledgement of the importance of doctors' communication with patients concerning the diagnosis of cancer. A recent editorial in the $B M J$ highlighted the difficulties many doctors have in communicating such news. ${ }^{1}$ If it is difficult for doctors, however, it is likely to be even more difficult for parents with newly diagnosed cancer to tell their children, while at the same time dealing with their own feelings and coming to terms with the implications themselves. ${ }^{2}$

There is evidence that good doctor-patient communication about the diagnosis and shared decision making over treatment is important and has a protective effect on patients' psychological adjustment. ${ }^{3}$ Little attention, however, has been paid to whether, what, and how children should be told about their parent's diagnosis. This responsibility has been left largely to parents unaided.

The little research that has been conducted on this issue suggests that when children are told of the diagnosis their anxiety levels are lower and communication within the family is improved, ${ }^{4}$ although factors such as the child's age have not been studied in detail. In addition, a large study in the United States has shown that in families where a mother has cancer, parents are often not aware of the extent of psychological symptomatology and distress of their children. ${ }^{5}$ No study to date has examined the timing, nature, and extent of communication between parents with cancer and their children or studied why parents do or do not talk to their children about such difficult and important
Editorial by Keeley

Leopold Muller Centre for Child and Family Mental Health, Department of Paediatrics and Child Health, Royal Free and University College Medical School, London NW3 2PF

Jacqueline Barnes senior lecturer in psychology Alan Stein professor

Tavistock and Portman NHS Trust, London NW3 5BA

Leanda Kroll senior registrar in child psychiatry

Olive Burke senior registrar in child psychiatry

Royal Free Hampstead NHS Trust, London NW3 2QG

Joanna Lee psychiatric social worker

Alison Jones consultant medical oncologist

Correspondence to: J Barnes j.barnes@rfc.ucl. ac.uk

BMJ 2000;321:479-82 
issues or inquired about what help parents have received or might have liked.

The relative frequency of life threatening illness in general among parents makes the issue of communication with their children an important public health matter. Breast cancer affects one in 12 women in the United Kingdom, about $30 \%$ of whom are likely to be diagnosed while they have children of school age living at home. ${ }^{6}$ Therefore families in which a mother has recently been diagnosed as having breast cancer are a particularly important group for study of the communication of the diagnosis to the children. We examined the nature of such communication, established whether parents were given any support or advice concerning the communication, and identified what support or guidance they might have wanted.

\section{Methods}

\section{Recruitment}

A consecutive series of women was approached at two breast cancer treatment clinics in north London hospitals over about 18 months. Those with stage I or stage II breast cancer (about $80 \%$ of cases) and who had at least one child aged between 5 and 18 years were approached by the breast surgeon or oncology consultant in outpatient clinics between four and six months after diagnosis. The women were given information and a consent form and, if interested, they contacted the research team. Approval was obtained from two local research ethics committees. Full informed consent was obtained, and it was explained that participation would not influence their ongoing medical care.

Thirty two women who fulfilled the criteria completed the study. Five women expressed interest but dropped out, and 16 who were approached did not make contact. A further 15 were interviewed but fell outside the study criteria, either because of characteristics of their illness or their children's ages. Their data are not presented in this paper. Interviews were conducted either in the home or in a research office. The mean age of the 32 women who fulfilled criteria and were interviewed was 43 (range 31-52) years. In total they had 56 children ( 35 boys) with a mean age of 12 years. Fourteen women had one child, 12 had two, and six had three. Most (27) were married or in a stable relationship; their socioeconomic status was classified according to the mother's occupation, unless she had never been employed (eight were professional; 14 were managerial; six were clerical; and four were manual); with a range of educational qualifications (10 had a degree; nine had A levels; 10 had GCSEs; and three had no qualifications). There was a bias towards middle class occupations, reflecting in part the population of the community. The number of children per family was evenly distributed in relation to maternal educational qualifications and social class.

\section{Outcome measures}

A semistructured interview incorporated certain questions from established instruments ${ }^{78}$ and was designed for this study to elicit both quantitative and qualitative information. Only the qualitative information is presented in this paper. The interview covered sociodemographic data followed by a combination of structured (yes/no) and open ended questions about the history of illness and treatment, communication with children and other family members and friends at specific times during the illness, children's understanding of the illness and treatment, and any emotional or behavioural problems in the children. Mothers were asked about their children's questions, reactions, and concerns. While the interviewer had a number of topics to cover, interviews were conducted in a manner that was sensitive to the interviewee and her narrative, allowing for prompts and exploration of topics raised spontaneously, to enhance the qualitative information elicited. ${ }^{9}$ All interviews were tape recorded and transcribed.

Transcripts were scrutinised by three members of the research team (JB, LK, JL), who analysed them using content analysis. ${ }^{10}$ The research group made lists of initial themes under broad headings (for example, reasons for talking or not talking to children; ways to help), and the additional major themes were identified on the basis of the interviews (for example, the questions children ask; what is the meaning of cancer; children's understanding of death). Transcripts were read again and passages relating to each theme

Reasons for wanting to withhold information from children

To avoid facing questions about cancer and death I think, I'm not just talking about children, I'm talking about anybody, you mention cancer to anybody and you're dead in front of them. (mother of 8 year old)

In the past she has said, "What's cancer?" And I've said "It's something that people die of" and I feel that if I mentioned it to her she would just worry so much. (mother of 7 year old)

He'll say "Just a minute Mummy, you've got cancer, are you going to die?" (mother of 9 year old)

To prevent children's distress I thought she would think after the mastectomy that I'm someone different or visualise something really horrific. That's what made me hold back. (mother of 10 year old)

He basically said he didn't want to talk about it because it made him too upset. (mother of 12 year old)

I feel that if I mentioned it to him he would just worry so much. (mother of 7 year old)

Children's understanding is not expected He knows that people can get sick and people can die and not come back but he's more likely to think that you'll die by drowning or getting run over by a bus than to actually fade away with an illness. For him the word "cancer" wouldn't have the same impact. (mother of 6 year old)

He asked me why I'd gone to the doctor's so I said because I'd got a lump in my breast and I wanted the doctor to have a look and he said "Have you got breast cancer? Will they cut it off? Will you die?" I was extremely taken aback that he had all that in his head about the implications of having a lump. (mother of 10 year old)

To preserve special family times

I was thinking I don't want her to be worried over Christmas, I don't want this Christmas to be any different to all the other lovely Christmases we've had. (mother of 16 year old) 


\section{Reasons for wanting children to have} information

\section{Belief in communicating}

We needed to be able to talk about how we felt about everything that had happened. (mother of 12 and 10 year olds)

Sooner or later they were going to know. Why not tell them straight away? I tell them frankly what is happening. I think they find it much easier to cope because they are ready for things. (mother of 16,13, and 12 year olds)

Desire to keep children's trust

You have got to be open with them. If you hide it and then you tell them after a few years then they would resent it. (mother of 15, 13, and 12 year olds)

We mustn't just brush them away. Children are aware and children can cope, so I've never pretended with him but I certainly accentuate the positive. (mother of 5 year old

Communication expected to alleviate children's distress

You could see the relief in her face when I said "Oh, the doctor said what I've got is curable, but I have to have treatment and my hair is going to fall off." (mother of 10 year old)

It is probably better to tell them straight away than leave it for a long delay. If you don't say anything it's worse for kids, especially as I was edgy. They can sense that something is wrong. (mother of 15 and 13 year olds)

collected together. Agreement was established between the three coders on the text applying to the initial themes by using the first 10 transcripts. Each further transcript was read by at least two members of the team to identify relevant content and any additional themes.

\section{Results}

\section{Timing of disclosure to children}

While nearly all women interviewed had talked to their partners from the early stages (22/29 at discovery of the lump; $20 / 26$ at visit to the general practitioner; 28/29 at outpatient appointment), few women told their children at that time. For mothers who decided to share information about their illness, children were usually told at the time of diagnosis $(39 / 56)$, but there was considerable variability in the extent to which children were told about the nature and possible consequences of the illness. At the stage of surgery 44 children had been told that their mother was ill but only 32 that her illness was cancer.

\section{Reasons for disclosure or non-disclosure}

The qualitative analysis was designed to explore mothers' decisions about making disclosures regarding their illness. There was considerable consistency in the reasons given for either discussing or not discussing the diagnosis with their children. The most common reason for avoiding discussion was to avoid facing children's questions and in particular those concerned with death. Mothers also talked about protecting their children by preventing anxiety and distress, which they expected to come from children's knowledge of their illness. Discussion was also avoided because children's understanding of the illness was not expected or to preserve special family occasions such as holidays. Those mothers who had communicated in detail with their children at an early stage in their illness, and often with details of the nature of cancer, said they thought children had a right to know. They also said that they wanted to keep their children's trust and to promote discussion in the family, which they hoped would alleviate children's anxieties about their changed appearance or the possibility of death.

\section{Ways to help parents think about communication} with their children

Mothers were asked whether they had been offered any help with talking to their children from a list of possible services and supports. While mothers had received careful discussion concerning the diagnosis and treatment of their illness, only a minority had been offered any kind of help with regard to communicating the information to their children, thinking about their children's reactions, or about the issues surrounding talking to children about serious illness. Many would have liked a meeting as parents, or as a whole family, with a health professional, preferably in their own home. Specifically they would have liked advice on ways to break news to their children based on detailed knowledge of child development. They also thought their children might benefit from talking directly to a healthcare professional, such as a nurse or the surgeon.

Mothers explained in their spontaneous comments that they wanted information about the most

\section{Help and facilities that mothers would have} liked

Knowledge of child development and age appropriate strategies

Talking to somebody who knew how the child interpreted things would be helpful because I was always of the opinion that he's far too young to understand, but the more you sit down and think about it I could have said more to him. (mother of 6 year old)

I would have liked some counselling as to how you break such shattering news to a 5 year old. (mother of 5 year old)

It would have been nice to have had the names of books about how to talk to children then [at diagnosis], even if we weren't in a state to listen to advice about how to break the news to the children. (mother of 8 year old)

Space and consideration for children in the hospital If there was any sort of crèche facility it would have made a huge difference. (mother of 5 year old)

The time I brought my son here there was nowhere else to go and he might not have necessarily been adequately prepared to see all these gadgets attached to his mother. (mother of 8 year old boy)

Preparation for the experience

I would have liked her to come with me one time, when I was seeing the surgeon or maybe after, just to be in the hospital and see it wasn't in any way a threatening or frightening experience. (mother of 18 year old)

A place that kids could come together in a group and talk, to share their feelings and make friends with them. They could say to each other, "Well my Mum's had that as well." (mother of 15 and 12 year old boys) 


\section{What is already known on this topic}

Retrospective studies report that many children are not told when a parent has a severe, life threatening illness

Communication between parents and children may reduce children's anxiety

\section{What this study adds}

Parents were most likely to initiate communication once a definite diagnosis was made, but many withheld the fact that their illness was cancer

Mothers gave clear reasons both for communicating and for not communicating with their children

A particular concern was about dealing with children's questions and comments about death

Many mothers would have liked to consult a health professional with experience in child development, preferably with both parents or as a family

appropriate language to use with children. They felt unsure about children's understanding of illness and death and wanted guidance on ways to communicate effectively. They also wanted to familiarise children with the medical environment and to have more amenities available for children when mothers attended appointments.

\section{Discussion}

Children are keen observers of their environment, and studies of family disruptions such as divorce have shown that they construct meaning for themselves, even blaming themselves for the ensuing changes. ${ }^{11}$ Women faced with a potentially life threatening illness may decide not to talk to their children about their condition. Our study has shown that some are reluctant to reveal their illness even after surgery. The results suggest that in general parents avoid communication with their children as a means of filtering information in the hope of controlling or minimising the children's difficulties.

There was a striking consistency in the spontaneous comments from mothers about why they did, or did not, discuss their illness. In many cases parents hoped to reduce the distress for their children and for themselves, and in particular they wanted to avoid mention of death. In addition, the extent of discussions was influenced by parents being unclear what children could understand, how they would react, and how to cope and respond when questions were asked.

It is now known that children have more potential to understand complex concepts of illness than many professionals had previously appreciated. ${ }^{12}$ Even if children are not told of the illness they soon become aware of changes in atmosphere at home and in their parent's health. Parents receiving a diagnosis of cancer need to be offered support and acknowledgement that they are part of a family unit, all the members of which are likely to be profoundly influenced by the illness and its treatment. Many parents need help to think about how they might talk to their children about the diagnosis and changes in family life. They are likely to benefit from discussion even if they decide not to communicate any details to their children. Such advice should take into account children's ages, the family's own communication style, and the parent's feelings about his or her illness and capacity to cope with the children's feelings and reactions.

More research is needed to investigate the best means of providing support and the consequences for the parents and children of more or less communication. Knowledge of ways that families respond to illness should have implications for undergraduate and postgraduate medical and nursing training and will have applications in other situations of loss and distress, such as coping with chronic physical illness in a parent or severe injuries resulting from road traffic accidents.

We are grateful to all the families who participated for taking time to talk about their experiences. Thanks to Lisa Brackenridge and Bernice Slagel for transcribing the tape recordings and to Rebecca Lindsey-Asher for help with the data entry. We also thank Alan Wilson, who gave information about the project to potential participants.

This work was undertaken by the Royal Free Hampstead NHS Trust, which received a proportion of its funding from the NHS Executive; the views expressed in this publication are those of the authors and not necessarily those of the NHS Executive.

Contributors: AS had the original idea for the study, was principal investigator, and is guarantor for this paper. AS, JB, $\mathrm{LK}$, and $\mathrm{OB}$ designed the protocol and together with $\mathrm{AJ}$ obtained funding. AS, LK, OB, JB, and JL interviewed the participants. JL and LK performed the qualitative analysis under JB's supervision, and JB conducted the statistical analysis. All authors discussed the main issues, interpreted the data, and edited the draft.

Funding: Royal Free Peter Samuel Fund.

Competing interests: None declared.

1 Buckman R. Talking to patients about cancer. No excuse now for not doing it. BMJ 1996;313:699-700.

2 Kroll L, Barnes J, Jones A, Stein A. Cancer in parents: communicating the diagnosis to children. $B M J 1998 ; 316: 880$

3 Fallowfield LJ, Hall A, Maguire P, Baum M, A'Hern RP. Psychological effects of being offered choice of surgery for breast cancer. BMJ 1994;309:448.

4 Nelson E, Sloper P, Charlton A, While D. Children who have a parent with cancer. A pilot study. J Cancer Educ 1994;9:30-6.

5 Welch AS, Wadsworth ME, Compas BE. Adjustment of children and adolescents to parental cancer. Cancer 1996;77:1409-18.

6 Cancer Research Campaign. Fact sheet 6. London: Cancer Research Campaign, 1996.

7 Lichtman RR, Taylor SE, Wood JV, Bluming AZ, Dosik GM, Leibowitz RL Relations with children after breast cancer. The mother-daughter relationship at risk.J Psychosocial Oncol 1984;2:1-19.

8 Woolley H, Stein A, Forrest GC, Baum JD. Imparting the diagnosis of lifethreatening illness in children. BMJ 1989;298:1623-6.

9 Britten N. Qualitative interviews in medical research. BMJ 1995;311:251-3.

10 Banister P, Burman E, Parker I, Taylor M, Tindall C. Oualitative methods in psychology: a research guide. Buckingham: Open University Press, 1994

11 Hetherington EM, Stanley-Hagan M. The adjustment of children with divorced parents: a risk and resiliency perspective.J Child Psychol Psychiatry 1999;40:129-40.

12 Rushforth H. Communicating with hospitalised children: review and application of research pertaining to children's understanding of health and illness. J Child Psychol Psychiatry 1999;40:683-91.

(Accepted 12 May 2000)

\section{Correction}

$\beta$ Blockade after myocardial infarction: systematic review and meta regression analysis

Several errors crept into this paper by Freemantle and colleagues (26 June 1999, pp 1730-7). In figures 1 and 2 some of the references were incorrectly cited and several bars did not agree with the odds ratios and 95\% confidence intervals. Readers may access the correct figures at www.bmj.com/cgi/content/full/318/7200/1730/DC2 